\title{
LA PROMESA OBLIGACIONAL EN LAS "PARTIDAS" COMO SEDE DE LA DOCTRINA GENERAL DE LAS OBLIGACIONES
}

\author{
Alejandro GuZMÁn BRITO*
}

RESUMEN: En las Siete Partidas (siglo XIII) hay un título especial dedicado a las promesas, que en todo corresponden a las estipulaciones del Derecho romano clásico. Ellas habían caído en desuso en la época postclásica de aquel Derecho, pero la concerniente doctrina de los juristas fue conservada en el Corpus iuris civilis, de Justiniano, de donde pasó a las Partidas. El "Ordenamiento de Alcalá" (siglo XIV) derogó la forma estipulatoria, aunque en la práctica ella no se usara. Con todo, los juristas continuaron estudiando este negocio aun en época moderna. La razón que se propone para explicar esta subsistencia teórica de una forma no practicada es que la doctrina de las estipulaciones contiene todos los extremos del fenómeno obligacional (clases, modalidades, extinción, etcétera) en su estado más puro y que, por ende, los juristas aprovechaban la promesa para exponer una materia para la cual no encontraban otra sede más adecuada; hasta que, ya en época moderna avanzada, sobre la misma base fue creada la doctrina general de las obligaciones de los códigos modernos y del chileno entre ellos.

Palabras clave: Promisión, estipulación, doctrina general de las obligaciones.

ABSTRACT: In the Siete Partidas (13th century), there is a special title dedicated to the promises, which met the requirements of classic Roman law. They fell into disuse during its postclassic epoch, but the relating doctrine of the jurists was preserved in Justiniano's Corpus iuris civilis, wherefrom it arrives to the Partidas. The "Ordenamiento de Alcalá" (14th century) abolished the stipulatory form, though it was not used. Still, the jurists continued studying this subject even in the modern epoch. The reason proposed to explain the theoretical subsistence of a non-practised form is that doctrine of stipulations contains all the extremes of the obligation phenomenon (types, modalities, extinction, etc.) in its purer condition and hence the jurists takes advantage of the promise to explain a subject for which there was not other adequate subject; until, already in modern advanced epoch, over the same base, it was created the general civil obligations doctrine of modern codes and Chilean code between them.

Key words: Promise, Stipulation, General civil obligations doctrine.

I. En las Siete Partidas (siglo XIII), el título $11^{\circ}$ de la partida $5^{\text {a }}$ está dedicado al tratamiento De las promissiones e pleytos que fazen los omes unos con otros, en razón de fazer, o de guardar o de complir alguna cosa. El título consta de 40 leyes. Le antecede aquel concerniente a la sociedad (De las compañías) y le precede el relativo a las fianzas (De las fiaduras). El esquema general de la $5^{\text {a }}$ partida es este:

\footnotetext{
* Catedrático de la Facultad de Derecho de la Pontificia Universidad Católica de Valparaíso. Dirección postal: Avda. Brasil 2950, Valparaíso, Chile. Correo electrónico: aguzman@ucv.cl
} 
Tít. $1^{\circ}$ De los empréstidos

Tít. 2o Del préstamo a que dicen en latín commodatum

Tít. $3^{\circ}$ De los condesijos a que dizen en latín depositum

* Tít. $4^{\circ}$ De las donaciones

Tít. 5० De las vendidas y de las compras

Tít. $6^{\circ}$ De los cambios que los omes fazen entrre sí e qué cosa es cambio

Tít. $7^{\circ}$ De los mercadores e de las ferias e de los mercados en que compran y venden las mercaderias e del diezmo del portadgo que han de dar por razón dellas

Tít. $8^{\circ}$ De los logeros e de los arrendamientos

Tít. $9^{\circ}$ De los navíos e del pecio dellos

Tít. $10^{\circ}$ De las compañías que fazen los mercadores e los otros omes unos con otros

Tít. 11 $1^{\circ}$ De las promissiones e de las otras posturas que fazen los omes unos con otros

Tít. $12^{\circ}$ De las fiaduras que se fazen con mandado o con placer de otro

Tít. $13^{\circ}$ De los peños que son empeñados por palabra o calladamente e de todas las otras cosas que a esta razón pertenecen

Tít. $1^{\circ}$ De las pagas e de los quitamientos e de los descontamientos a que dicen en latín compensatio e de las deudas que se pagan a los que las non deven

Tít. $15^{\circ}$ Como an los deudores a desamparar sus bienes quando non se atreven a pagar lo que deven e como devue ser revocado el enajenamiento que los debdores fazen

Lo que el código Alfonsino llama promission corresponde en todo a la stipulatio del Derecho romano clásico; en el lenguaje de cuyos juristas, por lo demás, también suele decirse promissio. Ambas palabras designan al mismo negocio, aunque desde diversos puntos de vista: si se lo considera desde la perspectiva del que va a resultar acreedor y estipula, se llama stipulatio; si, en cambio, de aquella del que va a resultar deudor y promete, se denomina promissio.

En el Derecho clásico ${ }^{1}$, la estipulación es un acto solemne de solemnidad verbal, ya que tiene que celebrarse mediante palabras prescritas. La iniciativa necesariamente la debe tomar el estipulante, con una pregunta del tipo: “¿Prometes darme 1.000?”, a que debe seguir inmediatamente una respuesta congruente, del tipo: “Prometo!”; el resultado es dejar civilmente obligado al promitente, que puede ser demandado con una acción in personam. La rigidez formal del acto se manifiesta en el uso prescrito de verbos como spondere o promittere, y varios otros, tanto en la pregunta como en la respuesta. Su flexibilidad, en compensación, radica en que por medio de una estipulación alguien se puede obligar a dar, hacer o no hacer cualquier cosa, según el designio práctico de las partes, y por cualquier causa, que no es necesario expresar. En un lenguaje moderno, podemos decir que la estipulación es formalmente típica pero materialmente atípica. Además, el mismo formalismo de la estipulación permite producir una gran variedad de efectos jurídicos, como consecuencia de otras tantas variaciones puramente formales introducidas en la pregunta del estipulante. Así, por ejemplo, si aquel, en vez de preguntar: “¿Prometes darme 1.000?”, dice: “¿Prometes darme 1.000 o un fundo?”, entonces se tiene una obligación de objeto alternativo, de modo que el deudor, aunque debe ambas cosas prometidas, se libera de su única obligación pagando con cualquiera de las cosas prometidas. Cuando la promesa se subordina a una condición negativa que consiste en la no realización de otra prestación, como: “¿Si no me dieres un fundo, prometes darme

${ }^{1}$ Para lo que sigue, es decir, para la stipulatio en el Derecho clásico, véase GUZMÁN BRITO (1996) pp. 9 y ss. 
1.000 ?", ahora se crea una obligación que llamamos facultativa, pues el deudor solo debe lo prometido, en este caso, los 1.000, pero se libera si da otra cosa, o sea, el fundo en el ejemplo. Si en vez de preguntar uno, son dos o más los que preguntan a coro o sucesivamente, o dos o más los que responden a coro o sucesivamente, ahora se tiene una obligación solidariamente activa o pasiva, ya que se crean varias obligaciones, pero todas con el mismo débito, de manera que el pago a cualquier acreedor o por cualquier deudor extingue todas las obligaciones de una vez; etcétera.

Debido a esta gran flexibilidad, la estipulación tuvo una importancia superlativa en el Derecho clásico. Fue a propósito de ella que la jurisprudencia estudió el fenómeno obligacional, porque es en dicho acto que la obligación se presenta en su estado más puro. De hecho, como insistiremos más adelante, la moderna doctrina o teoría general de las obligaciones deriva en su mayor parte de la doctrina romana de la estipulación.

Pero este negocio desapareció en la época postclásica, debido precisamente al formalismo que la impregnaba, que era su clave. El fenómeno empezó en la parte oriental del Imperio que, acostumbrada a la escrituración de los actos jurídicos, jamás comprendió la íntima estructura de la estipulación; tendió allí, pues, a convertirse en una cláusula de estilo, que era adosada a toda clase de negocios en que no se necesitaba, y con algunos de los cuales era incluso repugnante, como el testamento; pero se agregaba la cláusula de haber habido estipulación para evitar nulidades imaginadas o temidas. En la parte occidental, el desuso fue consecuencia de la vulgarización de la vida jurídica. En efecto, la forma estipulatoria, que era una artificialidad jurídica producto de una alta cultura de origen jurisprudencial, no podía mantenerse en un ambiente que tendía al naturalismo del tráfico jurídico y que carecía de juristas. De hecho, una constitución imperial del año 469, de León, ya prescinde de las palabras solemnes y declara válida toda estipulación "celebrada por el consenso de los contrayentes por cualesquiera palabras"2.

Fue el espíritu clasicista de Justiniano el que le impulsó a restaurar la estipulación clásica. En sus Digesta, en efecto, dedicó un título completo y muy extenso a las llamadas "obligaciones de palabras" (De verborum obligationibus) ${ }^{3}$, esto es, a las estipulaciones, en que conservó la doctrina de los juristas clásicos sobre este negocio, si bien se observan algunos relajamientos; y lo propio hizo en sus Institutiones, manteniendo la exposición del mismo que Gayo había presentado en su obra homónima, que Justiniano ahora reeditaba ${ }^{4}$. El orden de las Institutiones de Justiniano, en su parte pertinente, se presenta en el cuadro que sigue, en donde se han marcado con asterisco los títulos $15^{\circ}$ a $20^{\circ}$, pertinentes a las estipulaciones:

Lib. III

Tít. $1^{\circ}$ De hereditatibus quae ab intestato deferuntur

$[\ldots]$

Tít. $12^{\circ}$ De successionibus sublatis, quae fiebant per bonorum venditionem et ex senatusconsulto Claudiano

Tít. $13^{\circ}$ De obligationibus

\footnotetext{
${ }^{2}$ Cod. Iust. 8, 37, 10 .

3 Dig. 45, 1.

${ }^{4}$ Iust. Inst. 3, 15.
} 
Tít. 14 Quibus modis re contrahitur obligatio

*Tít. $15^{\circ}$ De verborum obligatione

*Tít. $16^{\circ}$ De duobus reis stipulandi et promittendi

*Tít. $17^{\circ}$ De stipulatione servorum

*Tít. $18^{\circ}$ De divisione stipulationum

*Tít. $19^{\circ}$ De inutilibus stipulationibus

*Tít. 20\% De fideiussoribus

Tít. $21^{\circ}$ De litterarum obligatione

Tít. 220 De consensu obligatione

Tít. $23^{\circ}$ De emptione et venditione

Tít. $24^{\circ}$ De locatione et conductione

Tít. $25^{\circ}$ De societate

Tít. 26 De mandato

Tít. 27o De obligationibus quasi ex contractu

Tít. $28^{\circ}$ Per quas personas nobis obligatio adquiritur

Tít. 29० Quibus modis obligatio tollitur

Lib. IV

Tít. $1^{\circ}$ De obligationibus quae ex delicto nascuntur

Tít. 2o Vi bonorum raptorum

Tít. 3o De lege Aquilia

Tít. $4^{\circ}$ De iniuriis

Tít. 50 De obligationibus quae quasi ex delicto nascuntur

Tít. $6^{\circ}$ De actionibus

$[\ldots]$

De esta guisa, la Edad Media recibió íntegramente la materia, y los glosadores y comentaristas pudieron incorporarla, así, en el sistema que con el tiempo vino a llamarse ius commune 5 .

No es extraño, en consecuencia, que las Partidas, un código intensamente romanista, como es sabido, se hayan creído en el caso de tener que tratar extensamente de la estipulación o promisión, en el título $11^{\mathrm{o}}$ de la partida $5^{\mathrm{a}}$, descrito al principiar. En general, debe decirse que la doctrina expuesta sobre esta materia es muy fiel a sus fuentes. Como ejemplo, baste citar la descripción que del negocio hace la ley $1^{\mathrm{a}}$, tít. $11^{\circ}$, part. 5a, la cual, en su parte pertinente, reza: "E fazese desta manera: estando presentes ambos los que quieren fazer el pleyto de la promissión, e diziendo el uno al otro: Prometesme de dar o de fazer tal cosa, diciendola señaladamente; e el otro respondiendo que si promete o que lo otorga de cumplir. E respondiendo por estas palabras, o por otras semejantes dellas, finca porende obligado, e es tenudo de cumplir lo que otorga, o promete de dar o de fazer [...]". Las leyes 2 a 4, por su lado, regulan detalladamente la forma promisoria, en todo coincidentes con las fuentes justinianeas.

II. No vamos a entrar en el estudio dogmático de la promisión alfonsina; por lo demás, ella ha sido tratada ampliamente por Arias Bonet ${ }^{6}$, en donde podrá encontrarse las noticias más importantes sobre aquel argumento. Pero sí vamos a tocar un problema histórico que presenta la promisión regulada en las Partidas, y que se vincula con la

\footnotetext{
${ }^{5} \mathrm{Al}$ respecto, véase: TRIFONE (s/d.) pp. 173 y ss.

${ }^{6}$ Arias Bonet (1966) pp. 285 y ss. Antes, NúNez Lagos (1950).
} 
disposición de la ley única del título $16^{\circ}$ del "Ordenamiento de Alcalá", célebre en la historia del Derecho europeo, que dijo: "Paresciendo que se quiso un ome obligar a otro por promision, o por algún contracto, o en alguna otra manera, sea tenudo de aquellos a quienes se obligó, e non pueda ser puesta excepción que non fue fecha estipulación, que quiere decir: prometimiento con ciertas solemnidades del derecho, o que fue fecha la obligación del contracto entre absentes; o que fue fecha a escribano público, o a otra persona privada en nombre de otro entre absentes; o que se obligó uno de dar o de facer alguna cosa a otro; mas que sea valedera la obligación o el contracto que fueren fechos en cualquier manera que paresca que alguno se quiso obligar a otro, e facer contracto con él".

La celebridad de esta ley deriva de que con ella se habría introducido el principio del consensualismo en el Derecho castellano, como régimen general para la celebración de negocios obligacionales, en lo cual, además, este habría sido precursor. A nosotros este tema en realidad no nos interesa ahora. Pero sí vale destacar que el exacto alcance de la citada ley fue derogar la promisión regulada en las Partidas; quiero decir: la rígida forma estipulatoria obediente al esquema pregunta-respuesta con palabras orales prescritas. En este sentido, el "Ordenamiento de Alcalá" se conecta históricamente con la ley del emperador León antes recordada, que operó lo propio en el ámbito del Derecho romano.

Que esto fue así, lo demuestra la glosa (1555) de Gregorio López. Este jurista se ve obligado a reconocer que en virtud de aquel ordenamiento, "hoy" (hodie) una estipulación no se vicia por el hecho de existir un intervalo entre la pregunta y la respuesta, lo mismo que no se vicia en los contratos consensuales; que una estipulación se puede concluir por medio de gestos, de la cabeza o los brazos por ejemplo, para asentir, aunque no se pronuncie palabra alguna; que un mudo puede, por ende, estipular y prometer, si le es posible oír; y que también puede lo uno o lo otro un sordo, si es capaz de hablar ${ }^{7}$. Nada de esto era lícito según el Derecho romano clásico y el Derecho de las Partidas. Eso demuestra que la promisión quedó sujeta al régimen de los actos consensuales, que no requieren forma, y que pueden ser celebrados por cualesquiera palabras orales o escritas, entre presentes o ausentes, por medio de un nuncio y hasta por gestos concluyentes. Todavía en un autor tan tardío como Juan Sala, en sus Institutiones Romano-Hispaniae, de 1798 (aunque cito la edición de 1830), se lee: "En España no reconocemos ninguna diferencia entre el pacto y la estipulación. [...]. En general, pues, debe tenerse por firme que entre nosotros por un pacto se puede rectamente operar todas aquellas cosas para las que, según las leyes Romanas, se exige estipulación", con invocación, por supuesto, del "Ordenamiento de Alcalá" en cuanto parte de la Novísima Recopilación", en donde había sido recogido.

III. De todo lo anterior se puede colegir que en Castilla la forma estipulatoria que reguló las Partidas fue pura y mera teoría, al menos desde el "Ordenamiento de Alca-

\footnotetext{
${ }^{7}$ LÓPEZ, Gregorio, gl. Gran pro (vers. Hodie tantum) ad Part. 5a, tít. 11º, ley $1^{\mathrm{a}}$.

8 SALA (1830) p. 146: "In Hispania nullam inter pactum er stipulationem agnoscimus differentiam. [...]. Generaliter itaque statuendum est, recte apud nos pacto peragi ea omnia, quia secundum leges romanorum stipulationem desiderant".

${ }^{9}$ Nov. Recop. lib. $10^{\circ}$, tít. $1^{\circ}$, ley $1^{\mathrm{a}}$.
} 
lá"10. Puede, en efecto, dudarse que alguien fuera a recurrir a dicha forma, tan rigurosa, cuando era totalmente lícito acordar consensualmente lo mismo que, según el Derecho romano y las Partidas, debería deducirse en estipulación.

Pero si esto fue así en Castilla, también lo fue en Indias. Desde luego no cabe dudar que la introducción de las Partidas en Indias fue con la derogación operada por el “Ordenamiento de Alcalá” en esta materia. Pero, además, casi a priori podría pensarse en cuán difícil hubo de ser que la forma promisoria echara raíces en suelo americano, y que resultara utilizada en la práctica. Evidentemente la prueba de esto es la más difícil que existe, porque atañe a un hecho negativo, esto es, a que en los archivos no existan promisiones documentadas según el modelo de las Partidas, al menos con una frecuencia que permita inducir su extendido empleo.

IV. Lo más sorprendente de todo, empero, fue que los juristas se dieron por notificados de la derogación en un sentido solamente extrínseco. Este fenómeno es un muy buen ejemplo de la fuerza espiritual que sobre ellos operaba el ius commune, y la consideración de supra-Derecho que el romano tenía en sus mentes. Imperturbablemente los juristas continuaron examinando y explicando el régimen de la promisión en las Partidas y de las estipulación en las fuentes justinianeas, como si se tratara de una figura vigente y actual, y solo de paso, a modo de aclaración, agregaban que tal o cual extremo suyo no era exigible en España en obsequio al "Ordenamiento de Alcalá". Las glosas de López, antes recordadas, son un buen ejemplo; pero el caso se repite constantemente. Aun a fines del siglo XVIII, los institucionistas castellanos, es decir, aquellos autores que exponían el Derecho de Castilla de acuerdo con el esquema de materias de las Institutiones de Justiniano, invariablemente reservaban en el lugar oportuno un lugar para el tratamiento íntegro de la promisión, como si gozara de entera aplicación.

Así lo podemos ver, por ejemplo, en la Ilustración del Derecho real de España $(1803)^{11}$ de Juan Sala (1731-1806):

Lib. I [Sobre la justicia y el derecho, y de las personas]

Lib. II [De las cosas, y del dominio y su adquisición y de los derechos reales]

Tít. $1^{\circ}$ De las división de las cosas, y del modo de adquirir su dominio

[...]

Tít. $4^{\circ}$ De los testamentos

[...]

Tít. $9^{\circ}$ De las obligaciones y contratos en general y transacciones

Tít. $10^{\circ}$ De las ventas y compras

Tít. $11^{\circ}$ De los retractos

Tít. $12^{\circ}$ Cuándo y cómo se paga la alcabala y el luismo por rescindirse o deshacerse la venta

Tít. $13^{\circ}$ De los logueros o de los arrendamientos

Tít. $14^{\circ}$ De los censos

Tít. $15^{\circ}$ De la compañía o sociedad y del mandato

\footnotetext{
10 Pero incluso desde antes. ARIAS BONET (1966) pp. 287 ss., ha demostrado que en toda la Edad Media castellana, no hay rastro documental del uso de la promisión alfonsina, si se dejan a un lado las conocidas cláusulas cautelares y de estilo, aparecidas ya en la Alta Edad Media por los notarios, del tipo "habiéndose añadido una estipulación" (stipulatione subnixa), que no reflejaban ninguna realidad.

${ }^{11}$ SALA (1837).
} 
*Tít. $16^{\circ}$ Del contrato verbal o de palabra Tít. $17^{\circ}$ De las fiaduras

Tít. $18^{\circ}$ De los peños o prendas

Tít. $19^{\circ}$ Del contrato literal y de los reales

Tít. $20^{\circ}$ De las donaciones

Tít. $21^{\circ}$ De los que llamados cuasicontratos

Tít. $22^{\circ}$ De los delitos y cuasidelitos, en cuanto producen pena pecuniaria

Tít. $23^{\circ}$ Modos de extinguirse las obligaciones

Como puede verse, Sala dedica el título $17^{\circ}$ al contrato verbal o de palabra, o sea, a la estipulación, que, por cierto, expone de acuerdo con la promisión de las Partidas.

Otro ejemplo viene ofrecido en el Febrero novísimo (1828) ${ }^{12}$ de Eugenio de Tapia (1776-1860):

Lib. I: De las personas

Lib. II: De las cosas

Tít. $1^{\circ}$ División general de las cosas. Del dominio y de las servidumbres

Tít. $2^{\circ}$ De las sucesiones hereditarias

Tít. $3^{\circ}$ De los mayorazgos, patronatos, capellanías y sus agregaciones

Tít. $4^{\circ}$ De las obligaciones pactos y contratos

Cap. $1^{\circ}$ De las diferentes clases de obligaciones y contratos

Cap. $2^{\circ}$ De los contratos consensuales, y en especial del de compra y venta

Cap. 3० De la venta de las cosas eclesiásticas

Cap. $4^{\circ}$ De los retractos o tanteos de las ventas

Cap. $5^{\circ}$ De los arrendamientos

Cap. $6^{\circ}$...

Cap. $7^{\circ}$ Del censo en general y del enfitéutico en particular

[...]

Cap. 12 De las compañías

Cap. $13^{\circ}$ Del mandato

Cap. $14^{\circ}$ De los poderes, de los procuradores y agentes de negocios

Cap. $15^{\circ}$ Del cambio o permuta

${ }^{*}$ Cap. $16^{\circ}$ De los contratos verbales y en primer lugar de las promesas

Cap. $17^{\circ}$ De las fianzas en común

Cap. $18^{\circ}$ De varias fianzas particulares

Cap. $19^{\circ}$ De las prendas e hipotecas

Cap. $20^{\circ}$ De los contratos reales y principalmente del préstamo o empréstito

Cap. $21^{\circ}$ Del depósito

Cap. $22^{\circ}$ De las donaciones y principalmente de la que se llama entre vivos

Cap. $23^{\circ}$ De la donación por causa de muerte

Cap. $24^{\circ}$ De las cesiones

Cap. $25^{\circ}$ De los contratos innominados, y en especial de la transacción y del contrato de obra

Cap. $26^{\circ}$ De los cuasicontratos

Cap. $27^{\circ}$ De varios actos legales accesorios a algunos contratos

Cap. $28^{\circ}$ De la extinción de las obligaciones procedentes de los contratos

Ahora es el capítulo $16^{\circ}$ el reservado a los contratos verbales, de los cuales el principal es la promesa.

Otro tanto acaece en las Instituciones del guatemalteco José María Álvarez, publicadas entre 1818 y $1820^{13}$.

12 TAPIA (1828).

13 ÁlvareZ (1982) véase el lib. III, título 16º, II, pp. 64 y ss. 
La explicación última del fenómeno ya ha sido apuntada: obedecía a la forma mentis de los juristas del ius commune, configurada desde la época de los glosadores, que inducía a los juristas a trabajar sobre una materia que en la práctica no siempre recibía aplicación. En esto, por lo demás, fueron continuadores de los propios juristas romanos, cuyo Derecho científico era nada más que un vasto y sofisticado esquema lógico, en sí mismo y como tal de difícil aplicación práctica, aunque en buena medida haya sido formado sobre bases reales, que los juristas reelaboraban hasta la exasperación a través de su inagotable casuística con que ponían a prueba los principios.

V. Pero aparte esta razón, había otra, que por lo demás también dejé apuntada al comenzar. Y esta razón es estrictamente científica; también pedagógica. La estipulación o promisión es la manifestación más pura y completa del fenómeno obligacional en todas sus variantes. Ni las obligaciones nacidas de actos reales, como las crediticias; o consensuales, como las que genera una compraventa o un arrendamiento; y menos las penales o derivadas de delitos civiles admiten la gran variedad de formas que pueden caber en una obligación nacida de estipulación. Piénsese, por ejemplo, en lo difícil que es concebir un mutuo bajo condición o un comodato que de origen a obligaciones alternativas. Mas, a partir del simple esquema: “¿Prometes dar tal? ¡Prometo!”, en cambio, por simple variación lógica en las formas de la pregunta se consigue aislar todas las posibilidades que puede asumir una obligación.

En consecuencia, la doctrina de la promisión, que en sí misma era nada más que pura teoría, cumplía en el Derecho común castellano e indiano -pero esto se puede decir para el de los demás países-, el papel de servir de sede a lo que hoy llamamos teoría general de las obligaciones, en el interior de un sistema jurídico, como era el común, que carecía de la noción sistemática moderna de las "partes generales". Tal es, si no me equivoco, la razón por la cual la jurisprudencia del Derecho común conservó su estudio y análisis pese a su impracticabilidad formal.

Históricamente ello permitió un tránsito muy natural al Derecho codificado, que sí contempla partes generales ${ }^{14}$, aunque no siempre se diga expresamente, y en todo caso conceptos generales o, mejor, generalizados. Lo que antes era promisión condicional o a plazo, en los códigos se convirtió en obligación condicional o a plazo; la estipulación

\footnotetext{
${ }^{14}$ El autor moderno que creó la "parte general" de las obligaciones fue Robert-Joseph Pothier en su Traité des obligations (1761-1764), de que los autores del Code Civil extrajeron la mayor parte de las normas del título $3^{\circ}$ : Des contrats ou des obligations conventionnelles en general de su libro III. Pothier compuso su esquema sobre las obligaciones así: la primera parte, que contiene la teoría general del contrato, tuvo como modelo el título 19: De inutilibus stipulationibus [véase el esquema institucional más arriba en el párrafo I de este trabajo], pues lo que en las Institutiones era la patología de las estipulaciones fue convertido en los requisitos del contrato. La segunda parte, sobre las diferentes especies de obligaciones, se inspiró en el título $18^{\circ}$ : De divisione stipulationum, con muchos complementos tomados de otros títulos sobre la misma materia (lo que en el título $15^{\circ}$ se dice sobre la condición y el plazo en las estipulaciones, fue convertido en obligaciones condicionales y a plazo; las estipulaciones con dos reos de prometer o estipular, tratadas en el título $1^{\circ}$, pasaron a ser obligaciones solidarias, etcétera). La tercera parte, acerca de los modos de extinguir las obligaciones siguió el modelo del título 290 Quibus modis obligatio tollitur. Pothier añadió un apéndice sobre la prueba de las obligaciones como cuarta parte, que no aparece en las Institutiones. Sobre esta materia: GUZMÁN BRITO (2006).
} 
solidaria fue reemplazada por la obligación solidaria; la estipulación penal por la cláusula penal; la estipulación con objetos alternativos por la obligación alternativa, etcétera. Si se miran las Partidas, se verá que todas estas materias aparecen tratadas en sede de promisión, como era en sus fuentes, esto es, en los Digesta y en las Institutiones. De paso, debo decir que el reemplazo no siempre fue feliz, porque a veces se torna en incomprensible cómo puede producirse algún efecto obligacional sin tener en cuenta la fuente, tal cual suele ocurrirles a los estudiantes de Derecho civil con las obligaciones alternativas o facultativas, para las cuales no aciertan a dar una explicación clara de cómo es posible que puedan nacer concretamente.

Un ejemplo revelador es el que ofrecen las Instituciones del Derecho civil de Castilla $(1771)^{15}$, de Ignacio Jordán de Asso (1742-1814):

Lib. I [sin rúbrica, pero trata de las personas]

Lib. II [sin rúbrica]

Tít. $1^{\circ}$ De la división de las cosas

Tít. 2o Del dominio, sus especies y modos de adquirirlo

Tít. $3^{\circ}$ De los testamentos y herencias

Tít. $4^{\circ}$ De la entrega y partición de la herencia y de las sucesiones ab intestato

Tít. 5० De las substituciones, mayorazgos y letrados

Tít. $6^{\circ}$ De las servidumbres

Tít. 7o De las prendas, hipotecas y censos

Tít. $8^{\circ}$ De los pactos y obligaciones en general

Tít. 9o De las donaciones

Tít. $10^{\circ}$ Del depósito y préstamo

Tít. $11^{\circ}$ Del empréstito y de las deudas

Tít. 120 Del mandamiento

Tít. $13^{\circ}$ De la compra y venta

Tít. $14^{\circ}$ De los arrendamientos

Tít. $15^{\circ}$ De la compañía o sociedad

Tít. $1^{\circ}$ De los cambios o permutas

Tít. $1^{\circ}$ De los contratos cuyo cumplimiento y sustancia penden de la suerte y casualidad

Tít. $18^{\circ}$ De las fianzas

Tít. $18^{\circ}$ De los delitos y penas en general

Tít. 20 Proporción que establecen las leyes de Castilla entre los delitos y penas

En este esquema no aparece ningún departamento reservado para el contrato verbal o promesa. Pero si leemos el título $8^{\circ}$ : De los pactos y obligaciones en general, observaremos que la materia de esa rúbrica general en realidad corresponde al contenido en el título sobre las promissiones de las Partidas alfonsinas.

Mas esto pertenece a otro capítulo de la historia de la formación del Derecho moderno. En lo que ahora interesa, me limito a proponer la explicación antes descrita para ese aparentemente extraño fenómeno, consistente en haberse mantenido durante tanto tiempo lo que bien podemos denominar un "relicto histórico": la promisión o estipulación, que pese a no ser practicada en la vida negocial, era examinada atentamente por los autores en sus exposiciones y seguramente estudiada no menos atentamente por los alumnos de Derecho en las universidades.

15 JordÁn de ASSO y DE MANUEL y RODRÍGUEZ (1792). 


\section{BIBLIOGRAFÍA CITADA}

Álvarez, José María (1827): Instituciones de Derecho real de Castilla e Indias (Nueva York, Lanuza Mendía y Cia., 2a ed.), 2 vols., reproducida anastáticamente en la serie "Fuentes", No 30, del Instituto de Investigaciones Jurídicas (UNAM., México, 1982), 2 vols.

ARIAS BONET, Juan A. (1966): "Recepción de formas estipulatorias en la Baja Edad Media. Un estudio sobre las promisiones de las Siete Partidas”, Boletim da Faculdade de Direito $\mathrm{N}^{\circ} 42$ (Coimbra).

GUZMÁN BRITO, Alejandro (1996): Derecho privado romano (Santiago, Editorial Jurídica de Chile).

GUZMÁN BRITO, Alejandro (2006): “De la "stipulatio" romana a la doctrina general de las obligaciones en los modernos códigos civiles", Roma e America. Diritto romano comune. Rivista di diritto dell'integrazione e unificazione del diritto in Europa e in America Latina $\mathrm{N}^{\circ} 22$ (Roma, Mucchi).

JoRdÁn DE ASSO, Ignacio y DE MANUEL Y RodríGUEZ, Manuel (1792): Instituciones del Derecho civil de Castilla (reimp. en 1984, Valladolid, Lex Nova, s. d.).

NúNEzZ Lagos, R. (1950): La estipulación en las Partidas y el Ordenamiento de Alcalá (Madrid, discurso en la Real Academia de Jurisprudencia y Legislación).

SALA, Juan (1830): Institutiones Romano-Hispaniae ad usum tironum hispanorum ordinatae (Matriti).

SALA, Juan (1837): Ilustración del Derecho real de España ordenada por [...] (Paris, Vicente Salvá).

TAPIA, Eugenio (1828): Febrero novísimo o librería de jueces, escribanos y abogados [...] por [...] (Valencia, Mompié).

TRIfOnE, Romualdo (s.d.): "La 'stipulatio' nelle dottrine dei glossatori", en: VV. AA., Studi di storia e diritto in onore di Enrico Besta per il XL anno del suo insegnamento (Milano, Giuffrè). 